\title{
Understanding the MIND phenotype: macrophage/microglia inflammation in neurocognitive disorders related to human immunodeficiency virus infection
}

\author{
Amanda Brown
}

\begin{abstract}
Tissue macrophages play important roles in maintaining homeostasis in most organs of the body including the brain where microglia represent the resident phagocytic cells of this compartment. The possibility of one day harnessing macrophage plasticity to treat or ameliorate disorders including obesity, cancer, organ damage, intestinal disorders, neurodegeneration, and cardiovascular disease in which these cells play a role, is a very exciting prospect. Inflammatory signaling is required for regenerative repair, healing, and pathogen clearance functions. However, when the inflammatory response persists in a chronic fashion over an extended period of time, damage to neurons is followed by neuronal injury and dysfunction. Macrophages in the brain are heterogeneous arising from tissues during embryogenesis, and in the adult, from bone marrow derived monocytes that enter through the blood-brain-barrier. While much of our insight regarding macrophage functional subtypes has been garnered through elegant studies in mice, which are amenable to genetic manipulation, far less is known about such cells in human tissues, and particularly in the brain under normal, disease, or injurious conditions. In this regard, non-human primate models for human immunodeficiency virus have been extremely useful for understanding the contribution of bone marrow-derived monocytes in neurological disease and their interaction and impact on the activation state of resident microglia in the brain. This review will focus on what has been learned from the rhesus macaque models about the types of macrophages present in the brains of animals with encephalitis. In vitro studies, which have used human blood monocytes differentiated into macrophages to address the question of macrophage subsets in HIV infection will be highlighted. Recent insights on macrophage phenotype and persistent inflammation in the brain in HIV-associated neurocognitive disorder from immunohistochemical studies on human autopsy tissue will be examined.
\end{abstract}

Keywords: Macrophage polarization; Neuroinflammation; HIV-associated neurocognitive disorder; Microglial activation; Neurodegeneration; Neuronal dysfunction; Osteopontin; Proinflammatory cytokine

\section{Introduction}

The possibility of one day harnessing macrophage plasticity to treat or ameliorate disorders including obesity, cancer, organ damage, intestinal disorders, neurodegeneration and cardiovascular disease in which these cells play a role, is a very exciting prospect. With the elegant studies done in mice, much has been learned about the ontogeny of tissue macrophages, their ability for local

Correspondence: abrown76@jhmi.edu

Johns Hopkins University School of Medicine, 600 North Wolfe Street/Meyer 6-181, Baltimore, MD 21287, USA proliferation and the recruitment of monocytes from the adult bone marrow under normal homeostatic conditions versus in disease states or in the case of injury [1-3]. In this review, some of the seminal findings from mice on monocyte-macrophage development will be highlighted and then the focus turned on the nervous system with an emphasis on recent findings on macrophage phenotype in non-human primates and humans as it relates to human immunodeficiency type 1 (HIV)mediated neuropathogenesis. 


\section{Review}

Macrophages were first identified in 1841 as inflammatory corpuscles in damaged brain, as foam cells by Virchow in 1846, stained by Weigert and Golgi in 1873, and its key function as a mediator of phagocytosis was reported by Metchnikoff in 1882 [4]. The central nervous system, and particularly the brain, represents the farthest reaches of the frontier, as any future translational therapeutic approaches must, based on our current understanding, surmount the blood-brain-barrier, penetrate into the brain parenchyma, and localize to the affected site in order to have a beneficial effect.

It is now well established, based on a series of recent elegant studies using mouse genetics, lineage fate mapping techniques, and transcription profiling, that embryonic monocytes give rise to the majority of tissue macrophages in an adult animal except for in the intestine, heart, and skin [1-3]. Moreover, these tissue macrophages are capable of self-renewal. However, in the context of neuronal injury and infection, patrolling monocytes/macrophages from the bone marrow will invade the brain. In this regard, trafficking of CCR2 expressing monocytes to the brain in a model of Alzheimer's disease, plays a key role in ameliorating the toxic effect of amyloid accumulation [5]. In the adult animal, myeloid cells develop in the bone marrow from a CD34+ hematopoietic stem cell that gives rise to a common myeloid progenitor that can migrate into tissues [6,7]. Turnover studies in mice suggest that monocytes circulate in the blood for 1-3 days before entering tissues where, depending on signals received from local resident macrophages [1], they differentiate into mature cells with distinct morphology and function. Whether different subpopulations of monocytes give rise to specific types of tissue macrophages is not currently fully understood, but there is agreement that the presence of the fractalkine receptor $\mathrm{CX}_{3} \mathrm{CR} 1$ marks inflammatory monocytes that migrate into tissues in response to its ligand $[8,9]$.

At least three distinct populations of monocytes have been identified in human blood based on the expression of the cell surface receptors: 1 ) $\mathrm{CD} 14^{\mathrm{hi}} \mathrm{CD} 16^{-}$(classical) which also express $\mathrm{CCR} 2^{\text {hi }}, \mathrm{CX}_{3} \mathrm{CR} 1^{\text {lo }}$ and represent $80-90 \%$ of total monocytes, 2 ) the $\mathrm{CD} 14^{+} \mathrm{CD} 16^{\mathrm{hi}}$ (nonclassical), and 3) the $\mathrm{CD} 14^{\text {hi }} \mathrm{CD} 16^{\text {lo }}$ (intermediate) proinflammatory monocytes that also express $\mathrm{CX}_{3} \mathrm{CR} 1$, and low levels of CCR2, and are found in the blood at 5-10\% [10]. This latter population is preferentially infected by in HIV [11] and infiltrates the brain during infection $[12,13]$. Moreover, transcriptional profiling suggests that distinct genetic programs distinguish the three subsets $[14,15]$. What we do not yet know is whether these subpopulations can be reprogrammed into different subtypes. In vitro, and likely in microenvironments within tissue compartments, specific cytokines can polarize monocytes to develop along different effector pathways that have been called M1 or M2, analogous to the nomenclature used for T-cell subsets [16-18]. Several excellent reviews discuss the discovery and spectrum of phenotypes and functional characteristics of these subtypes of macrophages $[18,19]$.

In addition to inflammatory-directed polarization, the determinants of macrophage morphology and function may in part, be governed by the cells in the microenvironment with which macrophages interact. For example, a subtype of macrophage found in the intestine, the muscularis macrophages, associate very tightly with enteric neurons to help regulate intestinal peristalsis [20]. Analogous to the microglia-neuron regulatory signaling mechanism using fractalkine ligand on neurons and fractalkine receptor on microglia, muscularis macrophages secrete bone morphogenetic protein 2 (BMP2), which activates the BMP receptor on enteric neurons [20]. Microglia, the resident macrophages in the brain, assume an ameboid shape when engaged in phagocytic functions. Microglia display an extensive ramified morphology under normal homeostatic conditions during which they continually make contact through extended finger-like projections to neurons in their vicinity [21,22]. Microglia also play critical roles in shaping neuronal networks during development, and in the adult animal by modulating synaptic transmission [21,23].

Within the brain, macrophage phenotype varies with their location in this tissue. Perivascular macrophages, as the name implies, are located intimately with vessels and enter from the blood circulation into the brain at a low level during normal conditions, and at higher frequency in the context of damage or invasion of the brain by a pathogen. Choroid plexus macrophages and meningeal macrophages, which are closely associated with the meninges, the thin blood vessels that line the brain, express MHC class II and costimulatory molecules. Parenchymal macrophages include the microglia population and cell surface markers such as CD68, Iba1, and CD163 stain both cell types [24]. Moreover, it is possible that infiltrating macrophages that move deeper into the parenchyma are able to do so because the appropriate transcriptional program has been initiated and recognized within the local microenvironment. Indeed, blood monocytes can home to the brain when microglia are experimentally depleted in mice [25]. However, the bone marrow-derived microglia are not able to penetrate deeply into the brain parenchyma, which suggests the possibility that they lack the genetic instructions to do so and/or that they do not receive the proper secondary signals perhaps because they are not in the correct location [25].

Traffic across the blood-brain-barrier is strictly regulated, but many pathogens are able to gain entry through monocytes, which are able to extravasate across. HIV enters the body through mucosal sites where it infects resident macrophages, dendritic cells, and CD4+ T-cells at these sites 
leading to dissemination throughout the lymphatic system. HIV enters the brain rapidly after infection. Entry into the brain was shown in a case of human iatrogenic transmission, and to occur within three to fifteen days depending on the experimental monkey model examined [26-29]. In the absence of treatment, encephalitis occurs in 20-30\% of infected individuals, which is characterized pathologically by the presence of multinucleated giant cells, microglia nodules, microgliosis, astrocytosis, and abundant CD68+ macrophages staining for HIV antigens [30]. As not all HIV-infected individuals develop CNS dysfunction, there is a role for host genetics in conferring susceptibility or resistance to the development of cognitive impairment [31].

The simian immunodeficiency virus (SIV) non-human primate models of HIV infection have been invaluable in adding to our understanding of the central role of macrophages as initiators of an inflammatory cascade, which ultimately results in neuronal damage and dysfunction $[32,33]$. Analyses of blood monocytes from infected individuals with HIV-associated dementia detected an expansion of the CD14+CD16+ subset [12], which was later confirmed in SIV-infected monkeys. Indeed, monocyte turnover in the bone marrow is a better predictor of progression to AIDS than CD4+ T-cell count and plasma viral load $[34,35]$. A very recent set of studies suggests a mechanism for CCR2/CCL2 signaling in the recruitment and trafficking of CD14 + CD16+ monocytes into the brain in HIV-associated cognitive impairment [36,37]. The CD14 + CD16+ monocytes that crossed an artificial blood-brainbarrier model as well as those found in the CSF of individuals with HIV-associated cognitive impairment, were found to preferentially express CCR2 [37]. Moreover, antibody against the tight junction protein JAM-A and adhesion molecule ALCAM was able to block the accumulation of CD14+CD16+ monocytes [38]. The macrophage marker CD163 is present on CD14 + CD16+ blood monocytes expanded in SIV encephalitis and these cells are believed to be the bone marrow derived CD34+ precursors of the CD163+ perivascular macrophages seen in the brain [39-41]. Moreover, CD68 + CD163+ macrophages accumulate in the CNS in SIV-infected monkeys and in human brain tissue from HIV-infected individuals [34,39-42]. In SIV encephalitis, productively infected CD14+CD16+ CD163 + CD45hi perivascular macrophages are abundant. The myeloid marker MAC387 is found on BrdU+ monocytes/macrophages in SIV-infected animals in the early stages of CNS invasion only when inflammation is abundant [43]. In contrast, in chronic lesions CD68 + CD163+ macs are most highly represented in SIV-infected animals and in HIV-infected human with encephalitis [34,39]. Moreover, MAC387 + CD163-CD68-CCR2- macrophages do not appear to be productively infected with HIV. Multinucleated giant cells, which are the hallmark of fulminant HIV replication in macrophages, expressed CCR2 and
CD68 [43]. Collectively, these data suggest the possibility that HIV-infected and uninfected M1-type macrophages may be present early, and as the host attempts to downregulate the immune response, M2-type macrophages become more abundant [44]. In in vitro monocyte-derived macrophages (MDM), HIV replication in M1 and M2 macrophages is reduced, however the extent of the inhibition varies with the stimuli used $[45,46]$. Microarray analyses on HIV-infected MDM have shown that the production of proinflammatory cytokines is increased through a TLR-independent pathway suggesting that HIV infection induces an M1-type milieu [47]. A proteomic study suggested that M1-HIV infected macrophages cocultured with T-regulatory cells can shift to an M2 phenotype, which was associated with neuroprotection [48]. Further study of the potential role played by M1 and M2 type macrophages in HIV CNS infection is required.

There are currently two approaches for investigating the contribution of human macrophage phenotype as it relates to HIV infection: 1) with in vitro culture models based on the isolation and differentiation of monocytes isolated from the blood (monocyte-derived macrophages or MDM) and 2) immunophenotyping using brain tissue obtained at autopsy. Monocyte isolation methods vary from low purity using adherence to plastic, to density gradient centrifugation, elutriation, or the use of positive or negative immunomagnetic bead selection for example for CD14+ cells. Each of these methods has their advantages and drawbacks, which relate to the level of purity, yield, and the inadvertent induction of cellular activation. Culture conditions can also vary widely and may make comparisons between laboratories difficult. This topic has been recently addressed and recommendations made [19].

We have used a standardized culture model for several years in conjunction with a recombinant HIV that encodes the enhanced green fluorescent (GFP) gene in a portion of the viral genome that is expressed early during infection [49-51]. Using flow cytometric analyses, we identified a consensus surface activation marker signature (SAMS), CD $14^{+} \mathrm{CD} 69^{+} \mathrm{CD} 86^{+} \mathrm{CD} 68^{\text {lo }}$ on a subpopulation of MDM in which HIV replication was active [52]. Interestingly, the presence of CD69, but not CD14 or CD86 on the cell surface was dependent on the expression of the viral protein Nef in the infected macrophage. Nef is essential for disease pathogenesis in vivo, for robust replication in primary T-cells and macrophages in vitro, and helps HIV to evade the immune response through multiple mechanisms [53-57]. Induction of CD69 expression on murine macrophages treated with LPS, TNF- $\alpha$ or IFN- $\gamma$ and LPS has been reported, however relatively little is currently known regarding the function of CD69 on this cell type [58]. One study suggests that CD69 may have a role in downregulating immune responses through TGF- $\gamma$ 
[59]. CD86 is a marker for M1-type macrophages and its presence together with CD69 suggests that these cells are highly activated. We understand what may at first seem paradoxical, that HIV would prefer to replicate in an activated cell, is that the virus has evolved to use host proteins as cofactors in the essential steps of reverse transcription, and transcription of the integrated proviral DNA. These cofactors are present at sufficient concentrations only in stimulated cells. At least in this in vitro model, both HIVdependent and -independent mechanisms are involved in the regulation of expression of these innate inflammatory surface proteins. It remains to be determined whether the phenotype identified will be recapitulated in human tissues in vivo, however CD14 + CD16 + CD69+ monocyte/ macrophages were previously reported to be expanded in the brain during HIV infection [12].

In regions of the world where therapy is widely available, the incidence of HIV encephalitis and full-blown dementia has greatly diminished [60,61]. However, the prevalence of milder forms of HIV-associated cognitive impairment has increased as people live longer with the infection. Importantly, comorbidities including aging, illicit drug use, exposure to antiretrovirals, cardiovascular disease, and insulin resistance could potentially contribute to cognitive impairment $[62,63]$. A major goal of the field is to identify the neuropathogenic mechanisms leading to the persistence of neuronal injury and dysfunction in HIV infection despite complete suppression of viral replication in the periphery. Much of the macrophage phenotype data that currently exists utilized autopsy tissue that predated the widespread use of antiretroviral inhibitors in the developed world.

Hence, there is a need to identify biological markers that could help predict risk for the development of cognitive impairment, and would serve a predictive function in assessing the efficacy of current treatments and for novel therapeutics in development. In this regard, a recent study suggests that individuals with asymptomatic neurocognitive impairment (ANI) have a 2-6-fold increased risk of progressing to further cognitive decline [64]. One recurring and prominent feature is the persistence of immune activation. Proinflammatory markers including IL-6, sCD14, sCD163 remain elevated in those on successful anti-viral therapy $[63,65]$. In part, the persistence of these factors is due to early HIV-mediated damage to the gastrointestinal tract in which microbial cell wall components are released into the circulation [66]. Moreover, the presence of these latter inflammatory mediators is associated with cognitive impairment in HIV [67].

Osteopontin (OPN) is a proinflammatory cytokine first described as early T-cell activation marker 1 that is expressed in several cell types including T-cells and tissue macrophages [68]. OPN was detected as a cytokine that was highly upregulated in the brains of monkeys with SIV encephalitis and later shown to also be elevated

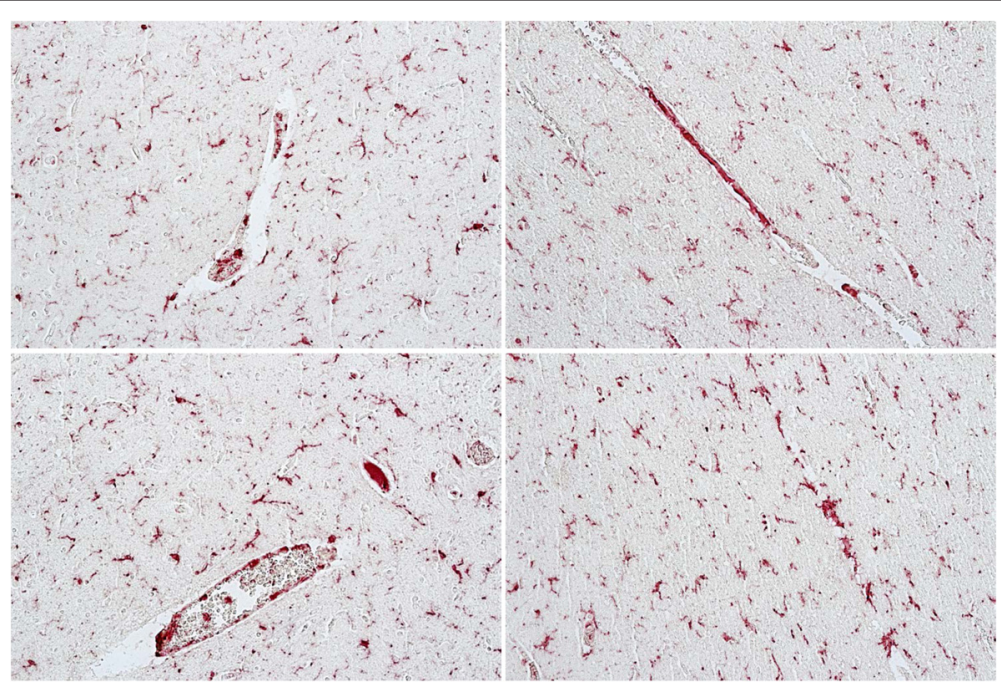

Figure 1 Abundant Iba1/AIF-1 positive parenchymal and perivascular macrophage/microglia (red color) costain for osteopontin (OPN) (brown color) expression in tissue from the occipital lobe of an HIV-infected individual with asymptomatic neurocognitive impairment (ANI). Paraffinembedded human autopsy tissue from the occipital lobe (National NeuroAIDS Tissue Consortium). Antigen retrieval was performed in citric acid buffer pH 6.0 and slides were stained sequentially with rabbit polyclonal antisera against Iba1/AlF-1 (SIGMA) overnight at $4^{\circ} \mathrm{C}$ followed by incubation with goat-anti-rabbitalkaline phosphatase (AP) secondary for $1 \mathrm{hr}$ at room temperature and developed with permanent FastRed Quanto (ThermoFisher) (red color). Slides were then incubated with mouse monoclonal antibody to OPN (MAB194, Maine Biotechnology) at room temperature for $2 \mathrm{hrs}$ followed by goat anti-mouse-horse radish peroxidase for $1 \mathrm{hr}$ and developed with 3,3'-diaminobenzidine (brown color). Images were taken on an Axio Observer A1 inverted microscope (Zeiss) at 20x magnification. Adjustment of the image brightness, contrast and sharpness was performed with Adobe Photoshop 5.5 using the same settings for each image. 


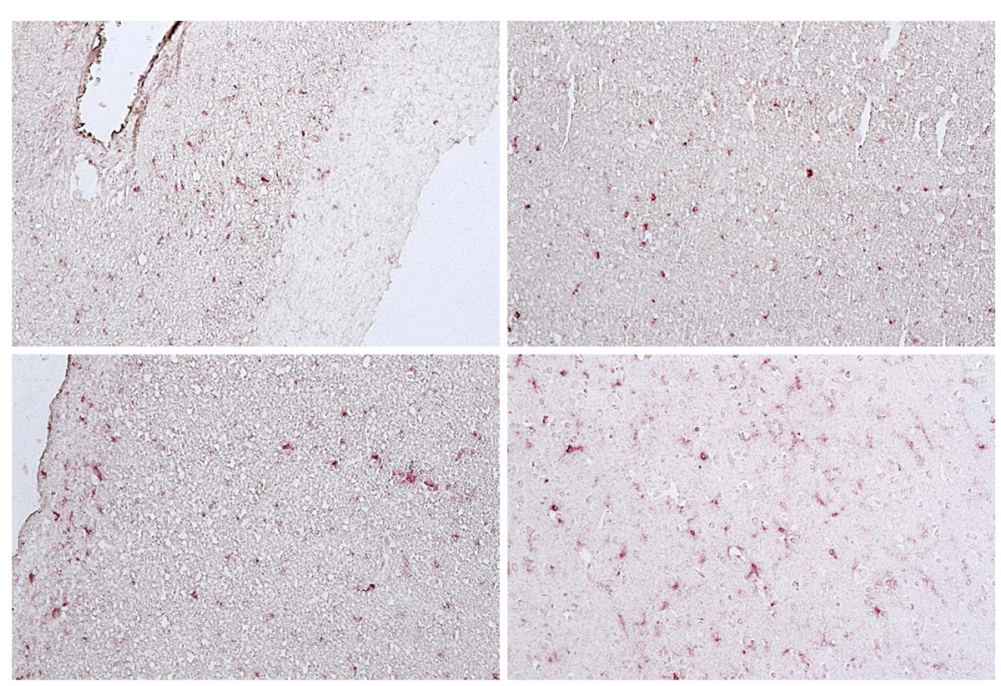

Figure 2 lba1/AIF-1 positive parenchymal macrophage/microglia (red color) costain for osteopontin (OPN) (brown color) expression in tissue from the occipital lobe of an HIV-infected individual with minor neurocognitive disorder (MND). Microglia with ameboid

morphology are more abundant than cells with a ramified phenotype.

in the CSF and brain of individuals with HIV-associated neurocognitive disorder [69,70]. Interestingly, OPN enhances HIV replication in macrophages by $50 \%$ through mechanisms that involve activation of the NF-kB responsive viral promoter, perhaps through integrin receptors and also by promoting cell-to-cell adhesion, which facilitates viral spread [69,71]. Interestingly, OPN levels in the plasma remain high despite undetectable HIV viral load, supporting other observations that inflammatory processes remain active [72]. Both HIV-infected and uninfected inflammatory monocytes have been shown to be key contributors to the inflammation seen in the brain [73]. We hypothesized that these cells were the major source for OPN in the brain of HIV-infected individuals. However, a recent immunohistochemical study on autopsy brain tissue suggests that astrocytes are also a source of OPN, although no significant differences in expression were seen between the HIV-infected and HIVinfected with cognitive impairment groups [74]. Unexpectedly, however, significant expression of OPN was detected in cortical neurons of brain tissue from those with HIV-associated cognitive impairment [74].

HIV-associated neurocognitive disorders (HAND) is an umbrella term to describe three levels of

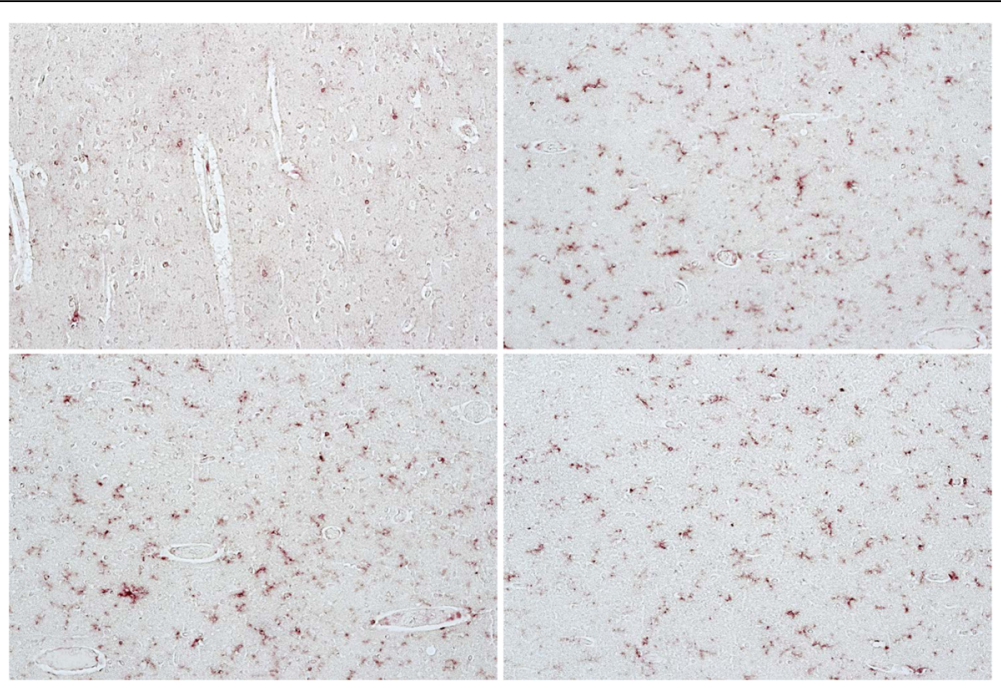

Figure 3 Abundant expression of osteopontin (brown color) in Iba1/AIF-1 positive parenchymal and perivascular macrophage/microglia (red color) in tissue from the occipital lobe of an HIV-infected individual with HIV-associated dementia (HAD). Osteopontin in HIV-infected HAD cases were significantly elevated compared to normal controls [74]. 
neurocognitive dysfunction: asymptomatic neurocognitive impairment (ANI) in which individuals show deficits (greater than one standard deviation) in two or more cognitive domains, but no impairment of activities of daily living (ADL); minor neurocognitive disorder has the same level of impairment as ANI, but ADLs are mildly affected and HIV-associated dementia (HAD) represents the most severe form of impairment in which deficits in two or more cognitive domains is greater than two standard deviations and there are a severe impact on ADLs $[75,76]$. In tissue from an HIV-infected individual with ANI, with very low viral load in the CSF (19 RNA copies/ml) or plasma (249 RNA copies/ml) who had been on antiretrovirals, an abundance of doublestained Iba-1/OPN perivascular macrophages and microglia and parenchymal microglia were detected (Figure 1). In a case with MND, the microglia appear to be predominantly of the ameboid type with few ramified processes (Figure 2). This patient at death despite being on therapy had a plasma viral load of $>48,000$ copies $/ \mathrm{ml}$, a CSF load of $148 \mathrm{copies} / \mathrm{ml}$ and was severely immunosuppressed with a CD4 T-cell count of 10. A case with HAD displayed microgliosis with abundant ameboid and ramified microglia in the parenchyma, and a high level of OPN expression (Figure 3). This individual at death had a high plasma viral load of $\sim 40,000$ copies $/ \mathrm{ml}$, a CSF load of 2747 copies/ml but a CD4 T-cell level of 299, not indicative of immunosuppression. Another study also found, as detected by the markers CD16, CD163, HLA-DR, and GFAP, that for macrophages/microglia and astrocytes, elevated levels of inflammation in the brain remained a common feature in HIV-infected individuals without evidence of encephalitis or productive viral replication in the brain [77]. Together these results highlight the variation in microglia activation that persists in the brain at the individual level and the need for reliable plasma and/or CSF markers that would allow clinicians to track smoldering CNS inflammation.

\section{Conclusion}

Much research remains to understand the communication between macrophages and other cells in the CNS. We need to identify the key inflammatory signals that are transmitted from the periphery to the brain and vice versa, which regulate homeostasis [21,78]. Comorbidities and host genetics are also important contributors that must be teased out and animal models will continue to play an essential role in these investigations. At the same time, human plasma and CSF have shown promise in uncovering the identity of potential biomarkers [79-85]. In the future, with regards to modulating macrophage phenotype in the CNS to counter neurotoxicity and promote regeneration [86], perhaps targeted delivery to the nasal compartment may provide an alternative portal to the brain [87]. We should all get excited about the small, yet significant steps that advance our understanding of macrophage phenotype, such that one day, we can make the giant leap to tackle disease and dysfunction in the MIND.

\section{Abbreviations}

GFP: Green fluorescent protein; HIV: Human immunodeficiency virus type 1: CSF: Cerebrospinal fluid; CNS: Central nervous system; Iba 1: Ionized calcium binding adaptor protein 1; OPN: Osteopontin; TLR: Toll-like receptor; MDM: Monocyte-derived macrophage; ANI: Asymptomatic neurocognitive impairment; MND: Minor neurocognitive disorder; HAD: HIV-associated dementia; HAND: HIV-associated neurocognitive disorders; SIV: simian immunodeficiency virus; ADLs: Activities of daily living.

\section{Competing interests}

The author declare that she have no competing interests.

\section{Acknowledgements}

We acknowledge the resources provided by The US National NeuroAIDS Tissue Consortium through the following grants: Manhattan HIV Brain Bank: U01MH083501, R24MH59724, Texas NeuroAlDS Research Center U01MH083507, R24 NS45491, National Neurological AIDS Bank 5U01MH083500, NS 38841, California NeuroAIDS Tissue Network U01MH083506, R24MH59745, Statistics and Data Coordinating Center U01MH083545, N01MH32002 and funding from the US National Institutes of Mental Health MH095646 awarded to A.B.

Received: 3 October 2014 Accepted: 27 January 2015

Published online: 26 February 2015

\section{References}

1. Epelman S, Lavine KJ, Randolph GJ. Origin and functions of tissue macrophages. Immunity. 2014;41:21-35.

2. Prinz M, Priller J, Sisodia SS, Ransohoff RM. Heterogeneity of CNS myeloid cells and their roles in neurodegeneration. Nat Neurosci. 2011;13:1227-35.

3. Ginhoux F, Greter M, Leboeuf M, Nandi S, See P, Gokhan S, et al. Fate mapping analysis reveals that adult microglia derive from primitive macrophages. Science. 2010;330:841-5.

4. Lasser A. The mononuclear phagocytic system: a review. Hum Pathol. 1983;14:108-26.

5. El Khoury J, Toft M, Hickman SE, Means TK, Terada K, Geula C, et al. Ccr2 deficiency impairs microglial accumulation and acclerates progression of Alzheimer-like disease. Nat Med. 2007;13:432-8.

6. Fogg DK, Sibon C, Miled C, Jung S, Aucouturier P, Littman DR, et al. A clonogenic bone marrow progenitor specific for macrophages and dendritic cells. Science. 2006;311:83-7.

7. Auffray C, Sieweke MH, Geissmann F. Blood monocytes: development, heterogeneity, and relationship with dendritic cells. Annu Rev Immunol. 2009;27:669-92.

8. Ancuta P, Rao R, Moses A, Mehle A, Shaw SK, Luscinskas FB, et al. Fractalkine preferentially mediates arrest and migration of CD16+ monocytes. J Exp Med. 2003;197:1701-7.

9. Ajami B, Bennett JL, Krieger C, McNagny KM, Rossi FM. Infiltrating monocytes trigger EAE progression, but do not contribute to the resident microglia pool. Nat Neurosci. 2011;14(9):1142-1149.

10. Ziegler-Heitbrock L, Hofer TP: Toward a refined definition of monocyte subsets. Front Immunol 2013;4:23. doi:10.3389/fimmu.2013.00023. eCollection 2013.

11. Ellery PJ, Tippett E, Chiu YL, Paukovics G, Cameron PU, Solomon A, et al. The CD16+ Monocyte Subset Is More Permissive to Infection and Preferentially Harbors HIV-1 In Vivo. J Immunol. 2007;178:6571-9.

12. Pulliam L, Gascon R, Stubblebine M, McGuire D, McGrath MS. Unique monocyte subset in patients with AIDS dementia. Lancet. 1997;349:692-5.

13. Zawada A, Rogacev K, Rotter B, Winter P, Marell R, Fliser D, et al. SuperSAGE evidence for CD14++CD16+ monocytes as a third monocyte subset. Blood. 2011;118:e50-61.

14. Ancuta P, Liu KY, Misra V, Wacleche V, Gosselin A, Zhou X, et al. Transcriptional profiling reveals developmental relationship and distinct biological functions of CD16+ and CD16- monocyte subsets. BMC Genomics. 2009;10: doi:10.1186/1471-2164-1110-1403. 
15. Ingersoll MA, Spanbroek R, Lottaz C, Gautier EL, Frankenberger M, Hoffmann R, et al. Comparison of gene expression profiles between human and mouse monocyte subsets. Blood. 2010;115:e10-9.

16. Mantovani A, Biswas SK, Galdiero MR, Sica A, Locati M. Macrophage plasticity and polarization in tissue repair and remodelling. J Pathol. 2013;229:176-85

17. Martinez FO, Helming L, Milde R, Varin A, Melgert BN, Draijer C, et al. Genetic programs expressed in resting and IL-4 alternatively activated mouse and human macrophages: similarities and differences. Blood. 2013;121:e57-69.

18. Mosser DM, Edwards JP. Exploring the full spectrum of macrophage activation. Nat Rev Immunol. 2010;8:958-69.

19. Murray PJ, Allen JE, Biswas SK, Fisher EA, Gilroy DW, Goerdt S, et al. Macrophage activation and polarization: nomenclature and experimental guidelines. Immunity. 2014;41:14-20.

20. Muller PA, Koscsó B, Rajani GM, Stevanovic K, Berres ML, Hashimoto D, et al. Crosstalk between muscularis macrophages and enteric neurons regulates gastrointestinal motility. Cell. 2014;158:300-13.

21. Paolicelli R, Kanchan B, Tremblay M-E. Fractalkine regulation of microglial physiology and consequences on the brain and behavior. Fron Cell Neuro. 2014;8: doi:10.3389/fncel.2014.00129.

22. Nimmerjahn A, Kirchhoff F, Helmchen F. Resting microglial cells are highly dynamic surveillants of brain parenchyma in vivo. Science. 2005;308:1314-8.

23. Xavier AL, Menezes JR, Goldman SA, Nedergaard M. Fine-tuning the central nervous system: microglial modelling of cells and synapses. Philos Trans $R$ Soc Lond B Biol Sci. 2014;369(1654):20130593. doi:10.1098/rstb.2013.0593.

24. Ransohoff RM, Cardona AE. The myeloid cells of the central nervous system parenchyma. Nature. 2010;468:253-62.

25. Varvel NH, Grathwohl SA, Baumann F, Liebig C, Bosch A, Brawek B, et al. Microglial repopulation model reveals a robust homeostatic process for replacing CNS myeloid cells. Proc Natl Acad Sci U S A. 2012;109:18150-5

26. Budka H, Costanzi G, Cristina S, Lechi A, Parravicini C, Trabattoni R, et al. Brain pathology induced by infection with the human immunodeficiency virus (HIV). A histological, immunocytochemical, and electron microscopical study of 100 autopsy cases. Acta Neuropathol. 1987;75:185.

27. Davis L, Hjelle BL, Miller VE, Palmer DL, Llewellyn AL, Merlin TL, et al. Early viral brain invasion in iatrogenic human immunodeficiency virus infection. Neurology. 1992:42:1736-9.

28. Glass J, Fedor H, Wesselingh S, McArthur J. Immunocytochemical quantitation of human immunodeficiency virus in the brain: correlations with dementia. Ann Neurol. 1995;38:755-62.

29. Koenig S, Gendelman HE, Orenstein JM, Dal Canto MC, Pezeshkpour GH, Yungbluth $\mathrm{M}$, et al. Detection of AIDS virus in macrophages in brain tissue from AIDS patients with encephalopathy. Science. 1986;233:1089-93.

30. McArthur JC, Brew BJ, Nath A. Neurological complications of HIV infection. Lancet Neurol. 2005;4:543-55.

31. Kallianpur AR, Levine AJ. Host genetic factors predisposing to HIV-associated neurocognitive disorder. Curr HIV/AIDS Rep. 2014;11:336-52.

32. Kraft-Terry SD, Gerena Y, Wojna V, Plaud-Valentin M, Rodriguez Y, Ciborowsk $P$, et al. Proteomic analyses of monocytes obtained from Hispanic women with HIV-associated dementia show depressed antioxidants. Proteomics Clin Appl. 2010;4:706-14.

33. Vázquez-Santiago FJ, Noel RJJ, Porter JT, Rivera-Amill V. Glutamate metabolism and HIV-associated neurocognitive disorders. J Neurovirol. 2014;20:315-31.

34. Burdo TH, Soulas C, Orzechowski K, Button J, Krishnan A, Sugimoto C, et al. Increased monocyte turnover from bone marrow correlates with severity of SIV encephalitis and CD163 levels in plasma. PLoS Pathog. 2010;6:e1000842.

35. Hasegawa A, Liu H, Ling B, Borda JT, Alvarez X, Sugimoto C, et al. The level of monocyte turnover predicts disease progression in the macaque model of AIDS. Blood. 2009;114:2917-25.

36. Williams DW, Veenstra M, Gaskill PJ, Morgello S, Calderon TM, Berman JW. Monocytes mediate HIV neuropathogenesis: mechanisms that contribute to HIV associated neurocognitive disorders. Curr HIV Res. 2014;12:85-96.

37. Williams DW, Byrd D, Rubin LH, Anastos K, Morgello S, Berman JW. CCR2 on CD14(+)CD16(+) monocytes is a biomarker of HIV-associated neurocognitive disorders. Neurol Neuroimmunol Neuroinflamm. 2014;1:e36.

38. Williams DW, Calderon TM, Lopez L, Carvallo-Torres L, Gaskill PJ, Eugenin EA, et al. Mechanisms of HIV entry into the CNS: increased sensitivity of HIV infected CD14 + CD16+ monocytes to CCL2 and key roles of CCR2, JAM-A, and ALCAM in diapedesis. PLoS One. 2013;8:e69270.
39. Soulas C, Donahue R, Dunbar C, Persons D, Alvarez X, Williams K. Genetically modified CD34 hematopoietic stem cells contribute to turnover of brain perivascular macrophages in long-term repopulated primates. Am J Pathol. 2009;174:1808-17.

40. Kim WK, Alvarez X, Fisher J, Bronfin B, Westmoreland S, McLaurin J, et al. CD163 identifies perivascular macrophages in normal and viral encephalitic brains and potential precursors to perivascular macrophages in blood. Am J Pathol. 2006;168:822-34.

41. Fischer-Smith T, Bell C, Croul S, Lewis M, Rappaport J. Monocyte/macrophage trafficking in acquired immunodeficiency syndrome encephalitis: lessons from human and nonhuman primate studies. J Neurovirol. 2008;14:318-26.

42. Roberts ES, Masliah E, Fox HS. CD163 identifies a unique population of ramified microglia in HIV encephalitis (HIVE). J Neuropathol Exp Neurol. 2004;63:1255-64.

43. Soulas C, Conerly C, Kim WK, Burdo TH, Alvarez X, Lackner AA, et al. Recently infiltrating MAC387(+) monocytes/macrophages a third macrophage population involved in SIV and HIV encephalitic lesion formation. Am J Pathol. 2011;178:2121-35.

44. Burdo TH, Lackner AA, Williams KC. Monocyte/macrophages and their role in HIV neuropathogenesis. Immunol Rev. 2013;254:102-13.

45. Cassol E, Cassetta L, Alfano M, Poli G. Macrophage polarization and HIV-1 infection. J Leukoc Biol. 2010;87:599-608.

46. Jimenez VC, Booiman T, de Taeye SW, van Dort KA, Rits MAN, Hamann J, et al. Differential expression of HIV-1 interfering factors in monocyte-derived macrophages stimulated with polarizing cytokines or interferons. Scientific Reports. 2012;2:1-7.

47. Brown JN, Kohler JJ, Coberley CR, Sleasman JW, Goodenow MM. HIV-1 activates macrophages independent of Toll-like receptors. PLoS One. 2008;3:e3664. Epub 2008 Dec 3662.

48. Huang $X$, Stone DK, Yu F, Zeng Y, Gendelman H. Functional proteomic analysis for regulatory $T$ cell surveillance of the HIV-1-infected macrophage. J Proteome Res. 2010;9:6759-73.

49. Brown A, Gartner S, Kawano T, Benoit N, Cheng-Mayer C. HLA-A2 down-regulation on primary human macrophages infected with an M-tropic EGFP-tagged HIV-1 reporter virus. J Leukoc Biol. 2005;78:675-85.

50. Brown A, Moghaddam S, Kawano T, Cheng-Mayer C. Multiple human immunodeficiency virus type 1 Nef functions contribute to efficient replication in primary human macrophages. J Gen Virol. 2004;85:1463-9.

51. Brown A, Zhang H, Lopez P, Pardo CP, Gartner S. In vitro modeling of the HIV-macrophage reservoir. J Leukoc Biol. 2006;80:1127-35.

52. Babu $R$, Brown A. A consensus surface activation marker signature is partially dependent on human immunodeficiency virus type 1 Nef expression within productively infected macrophages. Retrovirol. 2013;10:155.

53. Kestler HWI, Ringler DJ, Mori K, Panicali DL, Sehgal PK, Daniel MD, et al. Importance of the nef gene for maintenance of high virus loads and for the development of AIDS. Cell. 1991;65:651-62.

54. de Ronde A, Klaver B, Keulen W, Smit L, Goudsmit J. Natural HIV-1 Nef accelerates virus replication in primary human lymphocytes. Virology. 1992;188:391-5.

55. Chowers MY, Spina CA, Kwoh TJ, Fitch NJS, Richman DD, Guateli JC. Optimal infectivity in vitro of human immunodeficiency virus type 1 requires an intact nef gene. J Virol. 1994;68:2906-14.

56. Miller MD, Warmerdam MT, Gaston I, Greene WC, Feinberg MB. The human immunodeficiency virus-1 nef gene product: A positive factor for viral infection and replication in primary lymphocytes and macrophages. J Exp Med. 1994;179:101-13.

57. Tokarev A, Guatelli J. Misdirection of membrane trafficking by HIV-1 Vpu and Nef. Cellular Logistics. 2011;1:90-102.

58. Marzio R, Mauël J, Betz-Corradin S. CD69 and regulation of the immune function. Immunopharmacol Immunotoxicol. 1999;21:565-82.

59. Sancho D, Gómez M, Sánchez-Madrid F. CD69 is an immunoregulatory molecule induced following activation. Trends Immunol. 2005;26:136-40.

60. Heaton RK, Franklin DR, Ellis RJ, McCutchan JA, Letendre SL, LeBlanc S, et al. HIV-associated neurocognitive disorder before and during the era of combination antiretroviral therapy: differences in rates, nature and predictors. J Neurovirol. 2011;17:3-16.

61. Heaton RK, Clifford DB, Franklin Jr DR, Woods SP, Ake C, Vaida F, et al. HIV-associated neurocognitive disorders persist in the era of potent antiretroviral therapy: CHARTER Study. Neurology. 2010;75:2087-96.

62. Tovar-y-Romo LB, Bumpus NN, Pomerantz D, Avery LB, Sacktor N, McArthur JC, et al. Dendritic spine injury induced by the 8-hydroxy metabolite of efavirenz. J Pharmacol Exp Ther. 2012;343:696-703. 
63. Deeks SG, Lewin SR, Havlir DV. The end of AIDS: HIV infection as a chronic disease. Lancet. 2013;382:1525-33.

64. Grant I, Franklin DR, Deutsch R, Woods SP, Vaida F, Ellis RJ, et al. Asymptomatic HIV-associated neurocognitive impairment increases risk for symptomatic decline. Neurology. 2014;82:2055-62.

65. Lichtfuss GF, Hoy J, Rajasuriar R, Kramski M, Crowe SM, Lewin SR. Biomarkers of immune dysfunction following combination antiretroviral therapy for HIV infection. Biomark Med. 2011;5:171-86.

66. Brenchley J, Price D, Schacker T, Asher T, Silvestri G, Rao S, et al. Microbial translocation is a cause of systemic immune activation in chronic HIV infection. Nat Med. 2006;12:1365-71.

67. Ancuta P, Kamat A, Kunstman K, Kim E, Autissier P, Wurcel A, et al. Microbial translocation is associated with increased monocyte activation and dementia in AIDS patients. PLoS One. 2008:3:e2516.

68. Brown A. Osteopontin: A key link between immunity, inflammation and the central nervous system. Transl Neurosci. 2012;3:288-93.

69. Brown A, Islam T, Adams R, Nerle S, Kamara M, Eger C, et al. Osteopontin enhances HIV replication and is increased in the brain and cerebrospinal fluid of HIV-infected individuals. J Neurovirol. 2011;17:382-92.

70. Burdo TH, Ellis RJ, Fox HS. Osteopontin is increased in HIV-associated dementia. J Infect Dis. 2008;198:715-22.

71. Eger C, Cirelli K, Budiaman J, Brown A. Noncontiguous Protein Interaction Domains in Osteopontin Contribute to Enhance HIV-1 Replication. J Hum Virol Retrovirol. 2014;1: doi:10.15406/jhvrv.12014.15401.00003.

72. Burdo TH, Lo J, Abbara S, Wei J, DeLelys ME, Preffer F, et al. Soluble CD163, a novel marker of activated macrophages, is elevated and associated with noncalcified coronary plaque in HIV-infected patients. J Infect Dis. 2011;204:1227-36.

73. Kraft-Terry SDSA, Buch S, Gendelman HE. HIV-1 neuroimmunity in the era of antiretroviral therapy. Neurobiol Dis. 2010;37:542-8.

74. Silva K, Hope-Lucas C, White T, Hairston T-K, Rameau T, Brown A. Cortical neurons are a prominent source of the proinflammatory cytokine osteopontin in HIV-associated neurocognitive disorders (HAND). J Neurovirol. 2014, In press.

75. McArthur J, Steiner J, Sacktor N, Nath A. Human immunodeficiency virus-associated neurocognitive disorders: Mind the gap. Ann Neurol. 2010;67:699-714.

76. Antinori A, Arendt G, Becker JT, Brew BJ, Byrd DA, Cherner M, et al. Updated research nosology for HIV-associated neurocognitive disorders. Neurology. 2007;69:1789-99.

77. Tavazzi E, Morrison D, Sullivan P, Morgello S, Fischer T. Brain inflammation is a common feature of HIV-infected patients without HIV encephalitis or productive brain infection. Curr HIV Res. 2014;12:97-110.

78. Langford D, Masliah E. Crosstalk between components of the blood brain barrier and cells of the CNS in microglial activation in AIDS. Brain Pathol. 2001;11:306-12.

79. Mielke MM, Bandaru W, McArthur JC, Chu M, Haughey NJ. Disturbance in cerebral spinal fluid sphingolipid content is associated with memory impairment in subjects infected with the human immunodeficiency virus. J Neurovirol. 2010;16:445-56.

80. Bora A, Mohien CU, Chaerkady R, Chang L, Moxley R, Sacktor N, et al. Identification of putative biomarkers for HIV-associated neurocognitive impairment in the CSF of HIV-infected patients under CART therapy determined by mass spectrometry. J Neurovirol. 2014:Epub July 24.

81. Bandaru W, Mielke MM, Sacktor N, McArthur JC, Grant I, Letendre S, et al. A lipid storage-like disorder contributes to cognitive decline in HIV-infected subjects. Neurology. 2013;81:1492-9.

82. Valcour VG, Ananworanich J, Agsalda M, Sailasuta N, Chalermchai T, Schuetz A, et al. HIV DNA reservoir increases risk for cognitive disorders in CART-naïve patients. PLoS One. 2013:8:e70164.

83. Spudich S, Gisslen M, Hagberg L, Lee E, Liegler T, Brew B, et al. Central nervous system immune activation characterizes primary human immunodeficiency virus 1 infection even in participants with minimal cerebrospinal fluid viral burden. J Infec Dis. 2011;204:753-60.

84. Cassol E, Misra V, Dutta A, Morgello S, Gabuzda D. Cerebrospinal fluid metabolomics reveals altered waste clearance and accelerated aging in HIV patients with neurocognitive impairment. AIDS. 2014;28:1579-91.

85. Angel TE, Jacobs JM, Spudich SS, Gritsenko MA, Fuchs D, Liegler T, et al. The cerebrospinal fluid proteome in HIV infection: change associated with disease severity. Clin Proteomics. 2012;9: doi:10.1186/1559-0275-1189-1183.
86. Kigerl KA, Gensel JC, Ankeny DP, Alexander JK, Donnelly DJ, Popovich PG. Identification of two distinct macrophage subsets with divergent effects causing either neurotoxicity or regeneration in the injured mouse spinal cord. J Neurosci. 2009;29:13435-44.

87. Djupesland PG, Messina JC, Mahmoud RA. The nasal approach to delivering treatment for brain diseases: an anatomic, physiologic, and delivery technology overview. Ther Deliv. 2014;5:709-33.

\section{Submit your manuscript to a SpringerOpen ${ }^{\odot}$ journal and benefit from:}

- Convenient online submission

Rigorous peer review

- Immediate publication on acceptance

- Open access: articles freely available online

- High visibility within the field

- Retaining the copyright to your article

Submit your next manuscript at $>$ springeropen.com 